\title{
Serum amyloid A (SAA) variations in patients with cancer: correlation with disease activity, stage, primary site, and prognosis
}

\author{
H BIRAN,* N FRIEDMAN, $\dagger$ L NEUMANN, $\ddagger$ M PRAS,** \\ R SHAINKIN-KESTENBAUM $\dagger$
}

From the Departments of *Oncology, $\uparrow$ Nephrology, and $\ddagger$ Epidemiology, Soroka Medical Center, and Faculty of $\frac{\Omega}{\Omega}$ Health Sciences, Ben-Gurion University, Beer Sheva, and ${ }^{* *}$ Heller Institute of Medical Research, Tel-Aviv? University, Israel

SUMMARY Serum amyloid A (SAA) was determined in 160 patients with cancer. Active disease was associated with high titre compared with the titre in non-active condition $(31.8 v 5.8 \mu \mathrm{g} / \mathrm{ml}$, 응 respectively; $p=0.0002)$. SAA value showed a direct correlation with the stage of the disease: it was lowest at stages 1 and 2 and highest at the metastatic stage 4 (stage $1 v 4, \mathrm{p}=0.001$; stage $2 v 3$, $\subseteq$ $\mathrm{p}=0.05$ ). Cancers of the lung and unknown primary site were characterised by highly increased $₹$ SAA concentration. Initial SAA value had prognostic significance: a value below $10 \mu \mathrm{g} / \mathrm{ml}$ correlated $\vec{\oplus}$ with survival advantage, whereas a higher initial value indicated a greater likelihood of a poor $\%$ outcome (actuarial survival analysis $\mathrm{p}<0.001$ ). When stage was accounted for, initial SAA value had significant prognostic bearing on survival of patients with advanced disease (stages 3 and 4) but not on that of patients with limited disease (stages 1 and 2). Serial testing showed good concordance $\frac{\bar{O}}{0}$ between changes in SAA titre and clinical course.

SAA is an apolipoprotein that is mainly synthetised in the liver. It shows an instantaneous transient rise in response to various stimuli. ${ }^{1-3}$ In an extensive report Rosenthal et al described the association of active, especially metastatic, malignant diseases with an increase in SAA value. ${ }^{4}$ Their basic observation was repeated by other investigators, with some conflicting data regarding the ability of SAA to distinguish between local and metastatic disease. ${ }^{56}$ Our laboratory recently reported the potential value of SAA assay in the monitoring of prostatic cancer. ${ }^{7}$ That study was subsequently extended to additional malignancies.

In this study we defined the extent of disease by an international staging system, followed patient outcome, and analysed the prognostic significance of variations in SAA concentration.

\section{Material and methods}

\section{PATIENT POPULATION}

The distribution of patients according to diagnosis related in most cases to the primary organ of disease

Accepted for publication 26 February 1986
(Table 1). Evaluation of disease activity was based on $\overline{\overrightarrow{3}}$ physical examination, diagnostic imaging, and, when applicable, tumour markers (such as carcinoembryonic antigen (CEA)). Temporal response to intervention such as surgery, irradiation, or chemo용 therapy was recorded, as well as recently occurringo infection, inflammation, and myocardial infarction:Various staging systems were used in differentô diseases-such as tumour nodes metastases (TNM) system in breast, Dukes' classification in colorectal,음 and American Joint Committee staging in lung cancer. Equivalents of the various staging systems을 were determined following the International Union against Cancer guidelines ${ }^{8}$ for analysis.

Fresh serum samples were deep frozen and thawed ${ }^{N}$ later for SAA assay. SAA concentrations were deter- N mined by radioimmunoassay using purified $\mathrm{AA}$ fromo human amyloidogenic spleen of a familiak Mediterranean fever patient and rabbit antibody $\frac{\varnothing}{\varnothing}$ against human amyloid $\mathrm{A}$. Iodination of amyloid $\mathrm{A} \stackrel{\oplus}{?}$ was performed by the chloramine $T$ method. ${ }^{9}$ The $T$ assay was carried out as previously described. ${ }^{10}$ SAA ${ }^{\circ}$ titres were expressed in $\mu \mathrm{g} / \mathrm{ml}$ amyloid A equivalent.

Data processing was aided by the SPSS pro- $\mathbb{\mathbb { D }}$ grams. ${ }^{11}$ Actuarial survival was computed by the Kaplan-Meier non-parametric method. ${ }^{12}$ 
Table 1 Patient characteristics

\begin{tabular}{lrrr}
\hline Diagnosis (primary organ) & No of patients & \multicolumn{2}{l}{ Sex } \\
\cline { 2 - 4 } & & $M$ & $F$ \\
\hline Breast & 82 & & 82 \\
Colon & 20 & 11 & 8 \\
Rectum & 19 & 7 & \\
Colorectal & 2 & 3 \\
Stomach & 7 & 1 & 3 \\
Pancreas & 3 & 9 & 3 \\
Gall bladder & 1 & 4 & 1 \\
Lung & 12 & 2 & 1 \\
Melanoma & 5 & 3 & 3 \\
Kidney & 3 & 7 & 3 \\
Unknown & 3 & 4 & \\
Miscellaneous* & 10 & 4 & \\
\hline
\end{tabular}

*Urinary bladder one; thyroid (medullary) one; anus one; and lymphoma one.

Table 2 SAA and disease activity

\begin{tabular}{llc}
\hline Activity & No of patients & $\begin{array}{l}\text { Mean }(S D) S A A \\
(\mu g / m l)\end{array}$ \\
\hline Absent & 60 & $5 \cdot 8(7 \cdot 8)^{*}$ \\
Suspected & 35 & $10 \cdot 1(7 \cdot 7)$ \\
Present & 60 & $31 \cdot 8(52 \cdot 5)^{*}$ \\
Normal control & 20 & $2 \cdot 0$ \\
\hline${ }^{*} \mathrm{p}<0.0002$ & &
\end{tabular}

\section{Results}

SAA VALUE AND DISEASE ACTIVITY

Table 2 shows SAA value according to clinically evaluated disease activity. The concentration was significantly higher in active than in non-active disease $(31.8 \vee 5.8 \mu \mathrm{g} / \mathrm{ml}$, respectively; $\mathrm{p}=0.0002)$ and was intermediate in suspected cases.

\section{SAA VALUE AND STAGE OF DISEASE}

When patients were stratified according to stage of disease, a direct relation was found between SAA value and stage (Table 3 ). Titre was low in stages 1 and 2 and increased gradually towards stage 4 , where it reached a high value. Differences were significant between stages 2 and 3 and between stages 1 and 4 .
SAA VALUE IN SPECIFIC MALIGNANCIES

Table 4 shows that SAA value varied among the four main malignancies represented by our patient population-namely, breast, colorectal, pulmonary, and cancer of unknown primary site.

Cancer of the lung and cancer with unknown primary site were associated with remarkably high SAA titre compared with that found for mammary and large bowel cancer. As these malignancies were represented more commonly in an advanced stage, however, we had to compare different malignancies at a similar stage. Table 5 analyses patients with advanced disease only. Thus significant differences remained between breast cancer and both cancers of the lung and of unknown primary site.

INITIAL SAA VALUE AND COURSE OF DISEASE A cut off initial SAA titre of $10 \mu \mathrm{g} / \mathrm{ml}$ differentiated clearly between patients with favourable and those with unfavourable outcome. Fig. 1 displays actuarial survival of patients based on whether their initial SAA was below or above $10 \mu \mathrm{g} / \mathrm{ml}$. The median survival of patients who started with the higher titre was slightly over seven months, whereas patients with the lower titre had not yet reached the median at a follow up of 16 months $(\mathrm{p}<0.001)$. Further analysis was done to account for stage. Fig. 2 shows that SAA initial titre did not affect survival times of patients grouped together in stages 1 and 2, while it did affect patients grouped together in stages 3 and 4. Median survival of patients in the later stages was short of six months if they started in the higher SAA category, while it had not yet been reached in the other category $(p<$ 0.001 ).

Similarly, at 13 months' median follow up 65 of 106 patients with initial low $(<10 \mu \mathrm{g} / \mathrm{ml})$ SAA stayed free of disease in contrast to only four of 37 with high $(>10 \mu \mathrm{g} / \mathrm{ml})$ titre $(\mathrm{p}=0.001)$.

SERIAL SAA TESTING AND CLINICAL OUTCOME Forty seven patients had serial SAA determination. In each one the pattern of laboratory changes was confronted with the clinical course. A two fold change in titre was required to define either a decrease or an increase in SAA values. Table 6 shows these results.

Table 3 Relation between stage and $S A A$ value

\begin{tabular}{|c|c|c|c|c|}
\hline \multirow[t]{2}{*}{ Stage } & \multirow[t]{2}{*}{ No of patients } & \multicolumn{3}{|l|}{$S A A(\mu g / m l)$} \\
\hline & & $\overline{M e a n}(S D)$ & Median & Range \\
\hline $\begin{array}{l}1^{*} \\
2^{* *} \\
3^{* *} \\
4^{*}\end{array}$ & $\begin{array}{l}37 \\
38 \\
32 \\
45\end{array}$ & $\begin{array}{c}5 \cdot 86(8.64) \\
5 \cdot 39(3.96) \\
24 \cdot 8(55 \cdot 2) \\
40 \cdot 6(55 \cdot 2)\end{array}$ & $\begin{array}{r}4 \cdot 3 \\
4 \cdot 1 \\
5 \cdot 7 \\
15 \cdot 0\end{array}$ & $\begin{array}{l}1-11 \cdot 3 \\
0 \cdot 6- \\
1 \cdot 1-264 \\
1-270\end{array}$ \\
\hline
\end{tabular}

* 1 v $4 ; \mathrm{p}=0.001$

$* 2$ * 2 3; $\mathrm{p}=0.05$. 
Table 4 SAA values in specific malignancies according to primary site

\begin{tabular}{|c|c|c|c|c|c|}
\hline \multirow[t]{2}{*}{ Primary site } & \multirow[t]{2}{*}{ No of patients } & \multicolumn{4}{|l|}{$S A A(\mu g / m l)$} \\
\hline & & $\overline{M e a n}(S D)$ & Median & Range & Stage 4(\%) \\
\hline $\begin{array}{l}\text { Breast } \\
\text { Colorectal } \\
\text { Lung } \\
\text { Unknown }\end{array}$ & $\begin{array}{l}80 \\
28 \\
12 \\
10\end{array}$ & $\begin{array}{c}7.76(10 \cdot 8) \\
15.67(24.0) \\
62.4(79.9) \\
94.5(84.6)\end{array}$ & $\begin{array}{c}4 \cdot 75 \\
6 \cdot 4 \\
14 \cdot 9 \\
81 \cdot 5\end{array}$ & $\begin{array}{l}0 \cdot 06-63 \\
1 \cdot 2-99 \cdot 6 \\
1 \cdot 2-264 \\
2 \cdot 1-270\end{array}$ & $\begin{array}{l}16 \cdot 5 \\
25 \\
45 \cdot 5 \\
80\end{array}$ \\
\hline
\end{tabular}

Table 5 SAA values according to primary site in patients with advanced disease (stages 3 and 4)

\begin{tabular}{|c|c|c|c|c|}
\hline \multirow[t]{2}{*}{ Primary site } & \multirow[t]{2}{*}{ No of patients } & \multicolumn{3}{|l|}{$S A A(\mu g / m l)$} \\
\hline & & $\overline{M e a n ~(S D) ~}$ & Median & Range \\
\hline $\begin{array}{l}\text { Breast* } \\
\text { Colorectal } \\
\text { Lung* } \\
\text { Unknown* }\end{array}$ & $\begin{array}{l}30 \\
11 \\
10 \\
10\end{array}$ & $\begin{array}{l}12 \cdot 7(15 \cdot 9) \\
26.7(32.4) \\
73.5(83 \cdot 3) \\
94.5(84.6)\end{array}$ & $\begin{array}{r}6.0 \\
10.0 \\
44.4 \\
81.5\end{array}$ & $\begin{array}{l}1-63 \\
1 \cdot 6-99 \cdot 6 \\
1 \cdot 2-264 \\
2 \cdot 1-270\end{array}$ \\
\hline
\end{tabular}

*Breast $v$ either lung or unknown; $\mathrm{p}<0.001$.

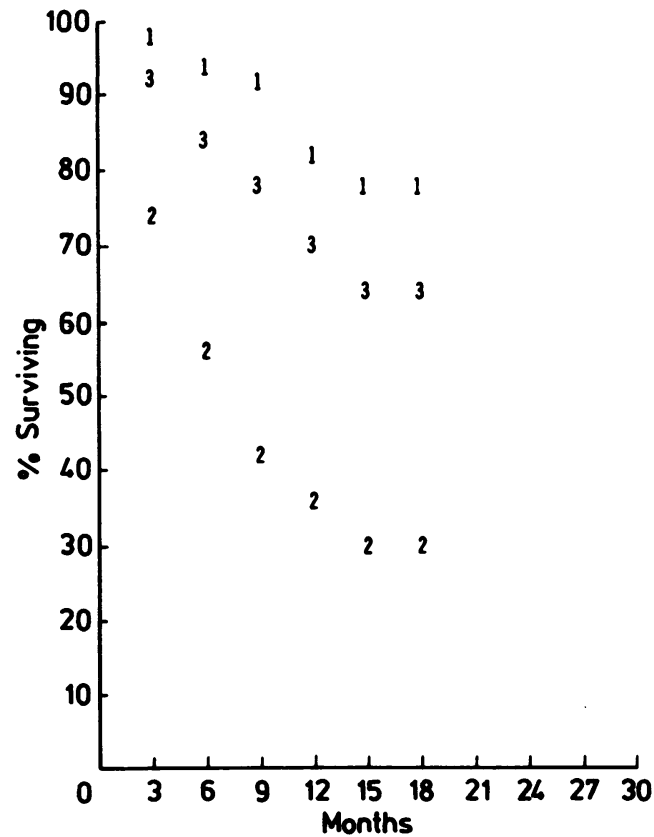

Fig. 1 Actuarial survival curve. Patients were divided according to initial $S A A$ values: 1 represents $S A A \leqslant 10$ (112 patients); 2 represents $S A A>10$ (39 patients); 3 represents all 152 patients.

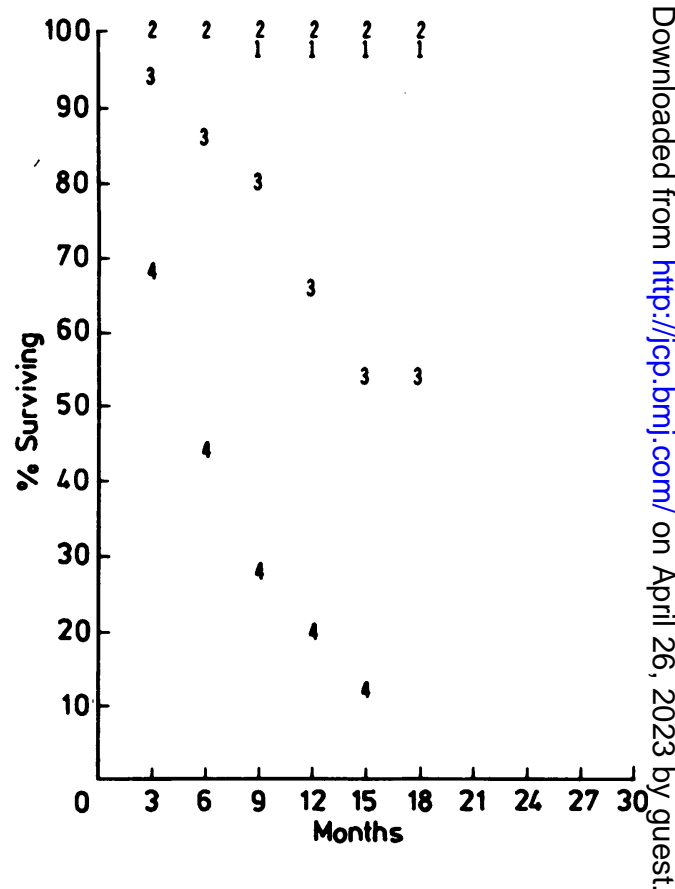

Fig. 2 Actuarial survival curve. Patients were divided according to initial $S A A$ values and stage: 1 represents $S A A \leqslant 10$, stages 1 and 2 (67 patients); 2 represents $S a$ $>10$, stages 1 and 2 (seven patients); 3 represents $S A R$ $\leqslant 10$, stages 3 and 4 (44 patients); 4 represents $S A A-\infty 10$, stages 3 and 4 (32 patients). 
Table 6 Clinical course $v S A A$ values in serial testing

\begin{tabular}{llllc}
\hline Clinical course & $S A A$ values & & \\
\cline { 2 - 5 } & No change & $\begin{array}{l}\text { Decrease } \\
>\text { two fold }\end{array}$ & $\begin{array}{l}\text { Increase } \\
>\text { two fold }\end{array}$ & Total no of patients \\
\hline No change & $23^{*}$ & 3 & 3 & 29 \\
Remission & 3 & $5^{*}$ & $10^{*}$ & 13 \\
Progression & 26 & 8 & 13 & 47 \\
\hline
\end{tabular}

"represents concordance.

Changes in SAA were in accordance with the clinical course in 38 of $47(80 \cdot 8 \%)$ cases.

\section{Discussion}

Several investigators collaborating with different laboratories studied SAA in malignancy and reported on its common increase in metastatic disease. Authors are not unanimous about the ability of SAA to distinguish between local and metastatic cancer, though reports favouring such an ability ${ }^{46}$ outnumber the discordant one. ${ }^{5}$ Conceivably, this controversy stems from the study of patient populations that are heterogeneous with regard to specific malignancy, stage, and distribution of metastatic sites. Furthermore, nonuniform staging does not permit us to compare different studies with regard to either "local" or "metastatic" disease, unless clear definitions are given.

The results of this study indicated that there is a concomitant rise in SAA value the more advanced the stage. Significant increase was found not only from stage 1 (early local disease) to stage 4 (metastatic disease) but also from stage 2 to stage 3 , which is still non-metastatic, though usually incurable. Certain tumours-that is, cancers of the lung and of unknown primary site seem to produce a particularly high SAA titre that cannot be accounted for by advanced stage alone. The observation regarding lung cancer has been mentioned, though not emphasised, previously. For instance, Rosenthal found an appreciable increase in small cell bronchogenic cancer, even in limited disease. ${ }^{4}$

An important objective of the study was to explore the prognostic value of SAA assay. As actuarial survival shows, lower initial titre correlated with significant survival advantage, in contrast to higher titre, which had unfavourable prognostic bearing on patients. In addition, serial assessment disclosed good concordance of laboratory and clinical ranges. Remission after treatment was paralleled by a decrease in SAA, while progression was accompanied, in most cases, by an increase.

Although SAA is not a tumour specific marker and does not fulfil the criteria for an "ideal marker," 13 we feel that it has potential value in the initial assessment of patients with cancer who have active disease, as well as in the monitoring of therapeutic results. It could be helpful when other available markers such as CEA are negative; it may also be added to a panel of other markers to increase their diagnostic power.

The assay may be selectively applied in diseases such as lung cancer, in which high titres facilitate interpretation of results.

\section{References}

${ }^{1}$ Benditt EP, Erikson N. Amyloid protein SAA is associated with high density lipoprotein from human serum. Proc Natl Acad Sci USA 1977;74:4025-28.

${ }^{2}$ Levin M, Pras M, Franklin EC. Immunologic studies of the major nonimmunoglobulin protein of amyloid. I. Identification and partial characterization of related serum component. $J$ Exp Med 1973;138:373-80.

${ }^{3}$ Rosenthal CJ, Franklin EC. Variation with age and disease of an amyloid A protein-related serum component. J Clin Invest 1975;55:746-53.

${ }^{4}$ Rosenthal CJ, Sullivan LM. Serum amyloid A to monitor cancer dissemination. Ann Intern Med 1979;91:383-90.

${ }^{5}$ Raynes JG, Cooper EH. Comparison of serum amyloid A protein and $\mathrm{C}$-reactive protein concentration in cancer and nonmalignant disease. J Clin Pathol 1983;36:798-803.

${ }^{6}$ Weinstein PS, Skinner M, Sipe JD, Lokich J, Zamcheck N, Cohen SA. Acute phase proteins or tumour markers. Scand J Immunol 1984;19:193-8.

${ }^{7}$ Kaneti J, Winikoff Y, Zimlichman S, Shainkin-Kestenbaum R. Importance of serum amyloid A (SAA) level in monitoring disease activity and response to therapy in patients with prostate cancer. Urol Res 1984;12:239-41.

${ }^{8}$ UICC-International Union Against Cancer. TNM-classification of malignant tumours. 3rd ed. Geneva: 1978.

${ }^{9}$ Hunter WM, Greenwood FC. Preparation of iodine-131 labelled human growth hormone of high specific activity. Nature 1963; 194:945.

${ }^{10}$ Shainkin-Kestenbaum R, Zimlichman S, Winikoff Y, Pras M, Chaimovitz C, Sarov I. Serum amyloid A in viral infection. Clin Exp Immunol 1982;50:503.

${ }^{11}$ Nie NH, Hadlai Hull C, Jenkins G. SPSS - statistical package for the social sciences. 2nd ed. New York: McGraw-Hill, 1975.

${ }^{12}$ Kaplan EL, Meier P. Nonparametric estimation from incomplete observations. Journal of the American Statistical Association 1958;53:457-81.

${ }^{13}$ Klee GG, Go VLW. Serum tumour markers. Mayo Clin Proc 1982;57:129.

Requests for reprints to: Dr H Biran, Department of Oncology, Soroka Medical Center, Ben-Gurion University, Beer Sheva 84101, Israel. 